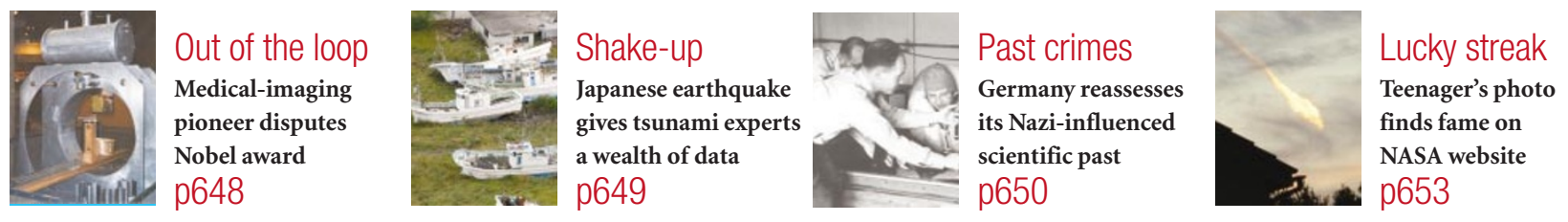

\title{
Health chiefs poised to step up US scrutiny of microbe research
}

\section{Erika Check, Washington}

The United States is set to implement formal structures for dealing with biological research that could aid terrorists, in the light of recommendations issued by the National Academy of Sciences.

An academy panel was charged with advising the federal government on the handling of biological findings that could provide information on engineering dangerous pathogens or weakening treatments against them. The study, supported by two nonprofit groups - the New York-based Alfred P. Sloan Foundation and the Nuclear Threat Initiative in Washington DC - began before the terrorist attacks of 11 September 2001. But it acquired new urgency after the anthrax attacks of that autumn, and with a batch of research findings whose open publication concerned some government officials.

The study's report, released on 8 October, recommends that the Department of Health and Human Services create a committee to advise it on issues related to biological research not intended to do harm, but that could conceivably threaten national security. The council also recommends that the National Institutes of Health reconstitute its Recombinant DNA Advisory Committee (RAC) to review such research in cases where local biosafety committees are unsure whether to allow the work to proceed.

The report defines seven categories of research that should always be reviewed in this way. Some are already reviewed by the RAC. But the report cautions strongly against restricting the types of research that scientists can pursue or publish.

"Vigilant self-government is the goal," says Gerald Fink, a molecular biologist at the Massachusetts Institute of Technology who chaired the panel.

Senior health-department officials say they will decide by early November whether to implement the report's recommendations. But Anthony Fauci, director of the National Institute of Allergy and Infectious Diseases, says that the National Institutes of Health has already decided to appoint a subcommittee to the RAC for dealing with national-security issues raised by biological research.

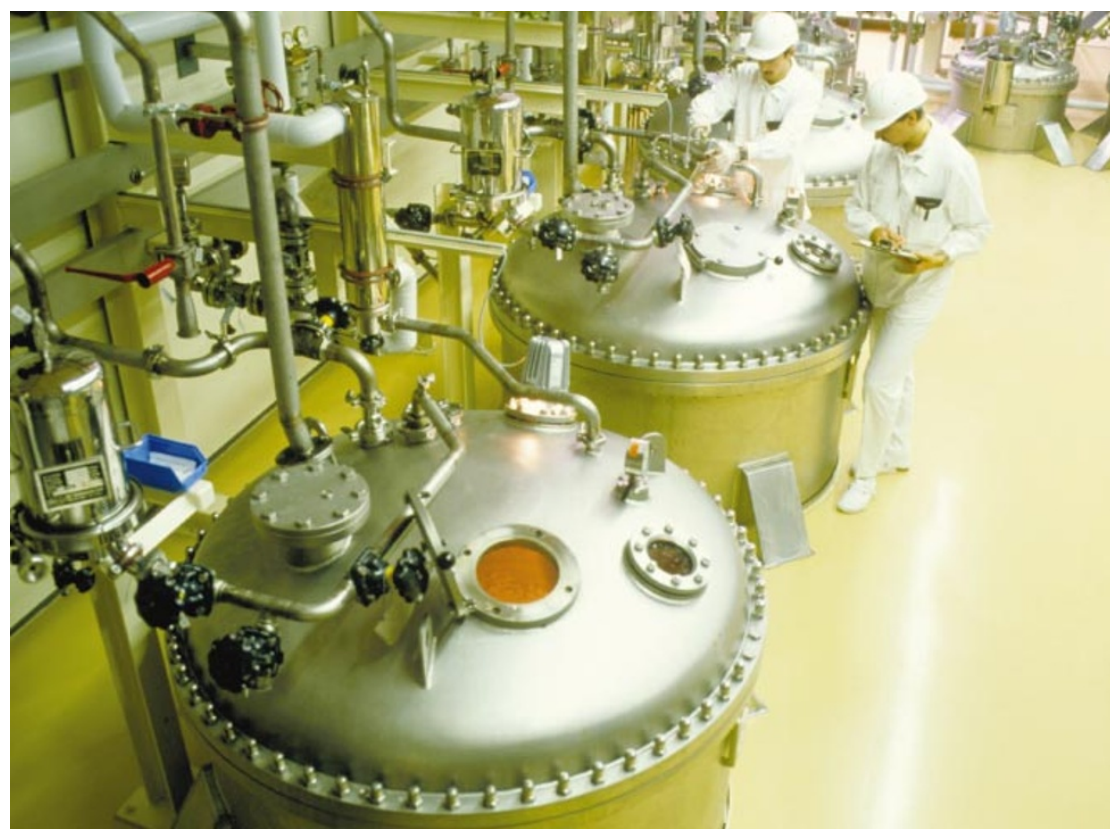

Think tank: an expert panel has drafted rules to monitor US labs that culture dangerous pathogens.

The kind of recommendations made by the report have been under discussion in the scientific and national-security communities for several months. Many scientists agree that a RAC-like body would be best placed to deal with issues raised by research in 'areas of concern', such as experiments that might change which animals a pathogen can infect.

Although the White House's Office of Science and Technology Policy had coordinated some of these discussions, its director John Marburger says the health department will be taking the lead on the issue. "We've been involved in some of the discussions so far, but the expertise for human biology lies within the department," he says.

Scientific groups, meanwhile, are relieved that the Fink panel has not proposed any further research restrictions, although they are still wary that its recommendations may be added to during their implementation. "We're going to have to watch as this goes forward," says Janet Shoemaker of the American Society for Microbiology. "It's a broad architecture but it has to be implemented in such a way that it doesn't inhibit research." Other observers say that the most difficult questions raised by biological research in the light of terrorism are only now starting to emerge.

For instance, they point out, the RAC operates in full public view, but it is unclear whether this will be the case if it starts to deal with security-related issues. And some say that the seven research types of concern in the report do not include those that will raise the most difficult issues. The experiments of concern all relate to microbiology and infectious disease - for instance, how to make a pathogen more infectious or resistant to antibiotics. They do not include other potentially threatening research, such as experiments in manipulating brain function.

"The experiments they've highlighted are the low-hanging fruit," says Gigi Kwik of the Center for Civilian Biodefense Strategies at Johns Hopkins University in Baltimore, Maryland. "We really need to do something about research that falls into the grey area. And filling in those details is going to be the difficult, squishy work ahead." 